\title{
Um exercício de descolonização da hipótese do Matriarcado na utopia Oswaldiana
}

\author{
Dolores Pereira Ribeiro Coutinho* \\ Josemar de Campos Maciel $^{* *}$ \\ Universidade Católica Dom Bosco \\ Campo Grande, Brasil \\ Paulo Benites ${ }^{* * *}$ \\ Universidade Estadual do Mato Grosso do Sul \\ Campo Grande, Brasil \\ Recebido em:30/04/2019 \\ Aceito em: 25/o7/2019 \\ O poeta e a criança, o primitivo e o louco, tudo isso é também povo. \\ Oswald de Andrade, Novas dimensões da poesia, 1992.
}

Resumo: Em 1950, Oswald de Andrade publicou dois textos cruciais para se pensar o teor político-filosófico de sua obra: "A crise da filosofia messiânica" e "Um aspecto antropofágico da cultura brasileira: o homem cordial". O presente texto tem como objetivo compreender o movimento de transformação do fazer poético de Oswald em exercício filosófico, transformação articulada tanto no plano da prática poética quanto no plano da reflexão teórica e crítica. Para tanto, acreditamos que o esforço do poeta em pensar as categorias de matriarcado e patriarcado ressoa como um exercício teórico fundamental para sua concepção filosófica do mundo, ainda que de maneira utópica.

Palavras-chave: Matriarcado. Patriarcado. Descolonização. Oswald de Andrade.

\begin{abstract}
In 1950, Oswald de Andrade published two crucial texts to consider the political-philosophical content of his work: "A crise da filosofia messiânica" and "Um aspecto antropofágico da cultura brasileira: o homem cordial". The present text aims to understand the movement of transformation of Oswald's poetic action in philosophical exercise, a transformation articulated both in the plan of poetic practice and in the plan of theoretical and critical reflection. To this end, we believe that the effort of the poet to think the categories of matriarchate and patriarchy resonates as a fundamental theoretical exercise for his philosophical conception of the world, albeit in utopian way.

Keywords: Matriarchy. Patriarchy. Decolonization. Oswald de Andrade.
\end{abstract}

Résumen: En 1950, Oswald de Andrade publicó dos textos cruciales para considerar el contenido político-filosófico de su obra: "A crise da filosofia messiânica" y "Um aspecto antropofágico da cultura brasileira: o homem cordial". El presente texto pretende comprender el movimiento de transformación de la acción poética de Oswald en el ejercicio filosófico, una transformación articulada tanto en el plano de la práctica poética como en el plan de reflexión teórica y crítica. Con este fin, creemos que el esfuerzo del poeta de pensar en las categorías de matriarato y patriarcado resuena como un ejercicio teórico fundamental para su concepción filosófica del mundo, aunque de manera utópica.

Palabras clave: Matriarcado. Patriarcado. Descolonización. Oswald de Andrade. 
Na Quinta-feira, o7 de setembro de 1922, O Jornal Folha da Noite estampou página com uma ilustração caracteristicamente modernista. A exclamação "Independência!" identifica o sol da liberdade e o pavilhão nacional brasileiro, que por sua vez serve como fundo para a figura viril de um índio, libertando-se de seus grilhões. Atrás da bandeira está uma índia, quer dizer, apenas a parte superior do seu corpo, o suficiente para assinalar liberdade com uma coroa semelhante à da estátua norte-americana. Ereto, o braço direito da índia sustenta, no lugar da tocha original, elos de uma corrente partida.

A ilustração acima descrita foi publicizada no centenário da Independência do Brasil, segundo os princípios de um movimento que objetivou "sacudir" a cultura nacional: a Semana de Arte Moderna de 1922. O movimento modernista pretendia afastar a nova arte das convenções de um passado europeizante.

A obra de Oswald de Andrade, herdeira genuína, e ao mesmo tempo engendradora do movimento modernista, encheu-se de "primitivismo", recheouse de elementos propagadores da liberdade do corpo e do espírito. O desejo de libertação colonialista se propagou pela verve do poeta e filósofo que interpretou a antropofagia como comunhão. Dois escritos filosóficos focam nosso olhar, ambos textos datados de 1950, A crise da filosofia messiânica e Um aspecto antropofágico da cultura brasileira: o homem cordial.

Incursionar através da filosofia oswaldiana é uma empreitada tão ousada quanto foram as reflexões do próprio filósofo. Ousadia traduzida em afirmações que contrariam estudos antropológicos e vestígios arqueológicos, são assertivas sobre a existência de uma sociedade Matriarcal que antecedeu à ordem Patriarcal.

Consta dos relatos dos viajantes pelo Brasil Colonial que hospedar alguém revestia-se de um ritual que envolvia as mulheres da taba no choro ao visitante. $\mathrm{O}$ choro, representação da emotividade característica do homem brasileiro, não se configurava como uma forma de boas maneiras, mas um gesto sincero de demonstração de apreço e solidariedade pelos percalços que o visitante passou e supostamente passará em sua vida. Esse traço da cordialidade do brasileiro foi retomado, por Oswald de Andrade, junto à obra de Sérgio Buarque de Holanda como configuração da emotividade característica do homem cordial, que teria dentro de si uma dualidade agressividade-cordialidade (ANDRADE, 1972, p. 141).

O filósofo exprimiu o pensamento de Briffault, na obra The Mothers (1927) ao interpretar a dualidade como componente da cultura primitiva que dedica afeto e auxílio ao membro do clã, aversão e inimizade ao resto do mundo. A dualidade é produto do que ele caracterizou como sendo a cultura matriarcal, que compreende a vida como devoração simbolizada na antropofagia, que é comunhão entre o devorador e o devorado, pois a devoração proporciona a possibilidade de ter o outro em si, a alteridade (ANDRADE, 1972). Faltou-lhe a percepção que chorar o visitante, atribuição das mulheres, que envolvia filhas e 
amigas, (ANDRADE, 1972, p. 141) não era o ato representativo de uma supremacia feminina, mas sim a consecução de uma tarefa que encarna a manifestação cultural de conduta apropriada ao sexo feminino em uma dada sociedade.

A devoração seria, para Oswald de Andrade, o componente básico da edificação da solidariedade social definida pela alteridade, presente no brasileiro primitivo, que desconhece o Deus católico, a imortalidade d'alma e a transcendência. É o reconhecimento do outro e sua incorporação ao eu, na busca da defesa mútua, devoração não é morte, mas permanência.

Pensar a antropofagia neste limiar, entendê-la enquanto problema e um desejo profundo de pensar a alteridade, é trabalho árduo. João Cezar de Castro Rocha é um dos críticos que propõe este pensamento; para tanto, ele acredita que devemos, primeiro, "desnacionalizar e desoswaldinizar o Manifesto Antropófago" (ROCHA, 2011, p. 668, grifo no original), pois só assim seremos capazes de responder à potencialidade da antropofagia. $O$ que equivale a dizer que precisamos de uma forma de depuração do conceito, para que ele seja representativo para além da personalidade de Oswald.

A ideia da antropofagia se tornou no Brasil um símbolo de resistência, inovação, uma busca pelo instinto de nacionalidade, muitas vezes tomada como mito, como bem observou Candido nos anos de 1940. Segundo Candido, em Estouro e Libertação (2011a), é preciso diferenciar essa "mitologia andradina" de um estudo "sinceramente objetivo" que não leva em conta a personalidade do autor. $\mathrm{O}$ que estimula uma investigação da antropofagia que atua no sentido de uma redescoberta do tema, para eventualmente produzir alguma purificação no conceito enquanto esforço de enucleação do sentido de experiências.

No cerne desta alegoria oswaldiana encontramos uma leitura que atua em um viés duplo: "da noção de antropofagia e dos relatos dos cronistas coloniais" (ROCHA, 2011, p. 649). De um lado, a noção de antropofagia ocupa lugar central na cultura brasileira, uma vez que é estratégia primordial em pelo menos três grandes eventos nacionais: o romantismo, o modernismo e o tropicalismo. Já por outro lado, atuam os relatos de viagens para o "Novo Mundo" que mencionam os atos de canibalismo que aconteciam na América dos séculos XVI e XVII. O enfoque destes relatos eram exatamente os rituais antropofágicos, como se pode ver em Duas viagens ao Brasil, de Hans Staden, publicado em 1557. Todo o movimento de apontar como desregrada e violenta a antropofagia fazia parte de um movimento de legitimação de esforços para legitimar a ocupação e a colonização do continente, depois de seu achamento por navegantes espanhóis e portugueses, a mando de reis com ambições de expansão de seus reinos e suas causas.

No Brasil, a antropofagia surge com o propósito de ser uma dignidade indispensável. O cenário do "Novo Mundo" era tecido como palco de barbáries, o que facilitava a sua ocupação e fruição por parte da hegemonia europeia. A reação 
contra esse estigma veio pela recuperação da própria antropofagia. João Cezar de Castro Rocha lembra a perspectiva de Gonçalves Dias no romantismo quando, em I-Juca-Pirama, diz que "o próprio título do poema demonstra que antropofagia não significa ausência de valores, mas, pelo contrário, caracteriza uma visão de mundo determinada" (ROCHA, 2011b, p. 649). Relembra ainda José de Alencar, que, em Ubirajara, "descreveu com perfeita vocação etnográfica o sentido do ritual antropofágico: através dele o índio busca apoderar-se da valentia e do valor inimigo" (ROCHA, 2011, p. 647).

De certo modo, essa leitura parece concordar com a perspectiva de Lúcia Helena ao afirmar que "a presença de um veio antropofágico e carnavalizante da cultura brasileira e na literatura brasileira não é uma propriedade exclusiva da obra de Oswald de Andrade" (HELENA, 1983, p. 92). Como apontou João Cezar sobre os românticos, a antropofagia sempre soou como um ideário nacional, muitas vezes antecipando o que Oswald propôs.

Contudo, foram os modernistas que aprofundaram esse movimento de releitura da antropofagia. Oswald de Andrade com Pau-Brasil, em 1924, Murilo Mendes com História do Brasil, em 1932, Mário de Andrade com Macunaíma, em 1928, Raul Bopp com CobraNorato, em 1931, são alguns exemplos desta "bibliotequinha antropofágica" (BOPP, 2008, p. 71).

Um dos motivos facilitadores do acirramento da antropofagia modernista foi a eclosão dos modelos vanguardistas europeus. Os intelectuais brasileiros mantiveram uma dialética necessária para apreender os elementos fundantes da visada antropofágica. Oswald de Andrade foi o "homem-ponte" deste período. Suas constantes viagens lhe permitiram alargar o horizonte das suas ideias, e seu contato com os artistas europeus da época foram propulsores na influência para os ideais modernistas. Travou contato com Picabia, Jules Superville, De Chirico, Picasso, Blaise Cendrars e muitos outros (BOAVENTURA, 1995).

Mário de Andrade reconheceu esse contato com a vanguarda exterior para a formação do pensamento modernista brasileiro: "o espírito modernista e suas modas foram diretamente importados da Europa” (ANDRADE, 1975, p. 236). Essa postura de reconhecimento de Mário de Andrade corrobora o pensamento de Oswald assinalado no Manifesto de 1928, quando diz que "só me interessa o que não é meu”. Antes, esses pensamentos são um gesto de apropriação do contexto cultural da época. Só depois "compreende-se que o vigor simbólico da antropofagia se relacione com a capacidade de enriquecer-se através da assimilação do alheio. Esse é o gesto que define o Manifesto Antropófago" (ROCHA, 2011, p. 654).

Isso pode ser percebido sob a ótica do primitivismo, segundo Oswald. $\mathrm{O}$ primitivismo, que foi um ideal apresentado em $A$ crise da filosofia messiânica, seria uma maneira de viver mais próximo à natureza, no sentido de manter uma relação intrínseca com valores vitais. O primitivismo está diretamente ligado ao 
hemisfério do Matriarcado, como assegura Oswald, isto é, a um modo de vida guiada por impulsos primários. Oposto está o hemisfério do Patriarcado, que idealiza o mundo civilizado:

E tudo se prende à existência de dois hemisférios culturais que dividiram a história em Matriarcado e Patriarcado. Aquele é o mundo do homem primitivo. Este o do civilizado. Aquele produziu uma cultura antropofágica, este uma cultura messiânica (ANDRADE, 1972, p.78).

A proposta parece uma busca pela essência das coisas. Nota-se em sua poética uma estrita ligação com a cultura antropofágica produzida por uma cultura matriarcal, ou seja, uma poética que representa o repúdio ao tecnicismo, conforme vemos no Manifesto da Poesia Pau-Brasil: "A língua sem arcaísmos, sem erudição. Natural e neológica. A contribuição milionária de todos os erros. Como falamos. Como somos" (ANDRADE, 2011, p. 22). Doutro modo, críticos como Eduardo Sterzi e Alexandre Nodari apontam a força antropofágica como a configuração de um direito estabelecido no pensamento político de Oswald de modo a garantir o espaço do primitivismo como ressignificação de "uma figuração da desmontagem linguística e vital que resta para quem experimenta a maturidade como um esgotamento e, no limite, como uma morte" (STERZI, 2018, p. 117).

Alexandre Nodari, em texto sobre a noção de Lei na obra oswaldinana, toma como ponto de partida o início do Manifesto Antropófago: "Única lei do mundo" (ANDRADE, 2011, p. 27). Para Nodari, o teor mais profundo do anúncio dessa lei está vinculado a um único preceito, como também notou Sterzi (2018), qual seja: "Só interessa o que não é meu. Lei do homem. Lei do antropófago" (ANDRADE, 2011, p. 27). A partir das leituras de Nodari e Sterzi sobre a noção de Lei no pensamento oswaldiano, notamos um movimento dialético entre o universal (Lei do homem) e do particular (Lei do antropófago). Tal movimento, como leem Sterzi (2018) e Nodari (2011), "parece ter a forma [...] de uma 'sanção legal do ilegal' ou ainda de 'uma lei que abole a lei' (semelhante àquela que encontraríamos na fórmula paradoxal de Maio de 68: 'É proibido proibir') (STERZI, 2018, p. 117).

Contudo, a partir do Manifesto antropófago, Nodari mostra como o "Direito Antropofágico" - expressão ausente no Manifesto, mas recorrente na Revista de antropofagia, lembrado por Sterzi (2018) - atravessa, no seu enigma mesmo, a obra de Oswald e transforma muito dela, a começar pelo próprio Manifesto, numa espécie de "longo comentário ao Direito que preceitua": "Única lei do mundo". Estamos, ao mesmo tempo, diante de uma lei - a lei da Antropofagia - que "já" estaria "em vigor" e que "rege[ria] a história humana" e de "uma norma programática, uma utopia a ser realizada contra o status quo"; 
estamos diante de "uma lei primitiva que cabe resgatar." (NODARI, 2011, p. 45557; STERZI, 2018, p. 118) mas também de uma lei ainda vindoura, que se deixará comunicar pelos meios e artes então mais modernos, o cinema, sobretudo, como afirma Sterzi (2018).

Neste ponto vale a pena recuperarmos a epígrafe deste texto, momento em que Oswald de Andrade entrelaça pensamento filosófico-político e fazer poético. Tal movimento abre a possibilidade de um mergulho mais fundo dialogando de perto com o que o poeta afirmara sobre a poesia: "A nova poesia restaura o reino da criança, do primitivo e do louco. Ouçamos Nietzsche...” (ANDRADE, 1992, p. 117). Para Eduardo Sterzi,

a poesia que nasce dessa "permanência da infância" se faz, simultaneamente, tarefa ético-política (que diz respeito aos modos de relação do poeta com os outros homens e com o mundo), mas também exercício heurístico (que diz respeito ao conhecimento outro do mundo). [...] Antes das normas estabelecidas para aprisionar o ser humano em suas funções sociais, estão as verdadeiras leis, ou os vários artigos da "única lei do mundo." que coincidem com a aventura e a liberdade, e que portanto não estão escritos em lugar algum, e por isso mesmo exigem que o poeta escreva sempre de novo - e sempre diferentemente (STERZI, 2018, p. 128).

Para além da permanência da infância da qual fala Sterzi, evidenciamos o espaço de resgate e permanência do primitivo. Tal espaço do primitivismo/matriarcado parece estar ligado ao mesmo exercício político filosófico de Oswald de Andrade de modo a reestabelecer as "verdadeiras leis", isto é, um retorno ao passado de forma consciente a fim de perceber que o retorno é sempre uma redefinição do presente. No cerne dessa discussão, encontramos a alteridade, vista não como elemento externo, mas como algo a ser incorporado pelo ritual antropofágico, com sua dinâmica de consumação e de reconfiguração. Sua antagonista, a individualidade, estaria presente na sociedade civilizada, edificada sobre a propriedade privada, característica do homem moderno, do egotismo do mundo e da ordem patriarcal. De resto, essa leitura do surgimento das instituições recupera e espelha o já citado trabalho de Briffault (1927).

A solidariedade social apresenta-se como possuindo como poderoso antagonista o egoísmo, presente na concepção escatológica de mundo, fundante e fundada no Patriarcalismo, que historicamente se apresenta como visão messiânica de vida. A redenção após a morte é o reconhecimento na vida eterna.

Oswald de Andrade contrapõe, e ao mesmo tempo unifica, a filosofia messiânica que ele denomina Patriarcal e a filosofia antropofágica, seu 
antagônico, Matriarcal. Para ele a primeira está presente, dialeticamente, na segunda, pela permanência do outro como crítica e possibilidade de superação. $\mathrm{O}$ retorno do matriarcado seria a capacidade de recuperar a solidariedade social. Faria parte de uma ondulação no pensamento humano promovida pelos percalços do mundo e pelo descrédito em uma redenção pós-morte.

Mas em que consiste o matriarcado oswaldiano?

O Matriarcado é um dos dois hemisférios culturais existentes; seu contraponto está no mundo civilizado, e é o Patriarcado. No mundo primitivo “... a sociedade não se dividia ainda em classes. O Matriarcado assentava sobre uma tríplice base: o filho de direito materno, a propriedade comum do solo, o Estado sem classes, ou seja, a ausência de Estado..." (ANDRADE, 1972, p. 80). Apresentando a obra do poeta-filósofo, Benedito Nunes enfoca a relação dialética entre esses dois hemisférios, na qual tese e antítese materializam o confronto entre o pré-histórico e o histórico, entre a vida primitiva e a civilização.

O Matriarcado é uma entidade mítica. Chegamos aqui ao ponto que mais nos chamou atenção: o Patriarcado teria surgido dentro de um processo social evolucionista, no qual os homens substituíram a devoração pela escravização. A propriedade privada do solo trouxe consigo a invenção do escravo e, com ela, a servidão. Sucessivamente, como corolário do processo de industrialização, a cristalização da prática e disciplinamento da venda da força de trabalho teria produzido a sociedade de classes. Desde que se inaugurou a supremacia de uma classe sobre a outra, se sustenta uma proposta messiânica de recompensas em outro mundo, que não aquele em que se dá a expropriação. O resultado do aparecimento da divisão do trabalho, e as classes sociais, foi a sobreposição, pelo poder religioso do messianismo monoteísta, pela classe sacerdotal. Oswald de Andrade (1972, p. 77-129) atribui a origem dessas suas "constatações" ao contato com J.J. Bachofen'e Engels.

Contudo, o marxismo militante, acusado por ele de fixar todo seu poder de fogo contra a propriedade privada, engajando-se na esfera patriarcal do haver, que rivaliza com a esfera matriarcal do ser. O filósofo denuncia o colapso produzido pelo fascismo soviético e acusa Stalin, chamado de novo Júlio César, de ter traído a dialética da História (ANDRADE, 1972, p. 118-119).

Se olharmos pelo ponto da vista estético, tais problematizações já estavam postas. A escrita literária de Oswald de Andrade pode ser compreendia pelo que chamamos de estilo miramar. Tal configuração estética é marcada acentuadamente pela ruptura. A ruptura representa a superação e a recusa aos costumes e aos modos de pensar correntes, e na prática também se manifesta pela quebra da fronteira entre prosa e verso. A esse respeito lembramos o que

${ }^{1}$ Sobretudo a obra Du regne de la mère au Patriarcat (1938). 
Antonio Candido constatou sobre seu estilo, diz que há um "trânsito livre entre prosa e poesia." (CANDIDO, 2011b, p. 55).

Apesar da acentuada marca do fragmentário da escrita literária de Oswald, há a consciência alerta de corresponder com os acontecimentos correntes. Para Antonio Candido, "uma das perfeições de um romance é o fato de conter certos aspectos fundamentais de sua época” (CANDIDO, 2011a, p. 23). Ou seja, a produção artística de Oswald de Andrade é uma produção na qual se pode perceber as reverberações das crises que afrontam a sociedade. A sua literatura está materializada na palavra, e a palavra de Oswald de Andrade é bastante sensível para manifestar os aspectos fundamentais de sua época. Não deve estranhar, portanto, o seu esforço de assimilar e traduzir em uma elaboração mais sistemática uma discussão que envolvia um esforço de grande fôlego para produzir uma figura racional da construção da civilização. Por mais ambíguo que isso possa ter sido ${ }^{2}$.

As Memórias Sentimentais de João Miramar, por exemplo, são publicadas no mesmo ano do Manifesto da Poesia Pau-Brasil. Um ano depois, em 1925, Oswald publica o poemário Pau Brasil na tentativa de executar o que propusera no manifesto. Essas duas obras são o arranque da produção de maior fôlego de Oswald de Andrade que compreende o intervalo entre as décadas de 1920-1930. Nesse intervalo há a publicação de, além dessas duas obras, A estrela do absinto, Caderno de poesia do aluno Oswald de Andrade, ambas em 1927, e em 1929 termina a redação de Serafim Ponte Grande, que fora publicado somente em 1933.

Os dois romances - Miramar-Serafim - marcam a revolução que Oswald promove no cenário nacional das letras. Sobre a recepção desses dois romances, Antonio Candido escreveu: "Desde a linguagem, nua e incisiva, toda concentrada na sátira social, até a despretensão da atitude literária, que não se preocupa em embelezar a vida" (CANDIDO, 2011a, p. 13). A escrita oswaldiana é uma síntese socialista que emprega a rebeldia anárquica de libertação da linguagem presa aos velhos costumes da tradição.

Ambos os romances podem ser considerados como a "fase da negação" (CANDIDO, 2011a, p. 21) de Oswald de Andrade. Dialogando de perto com os principais pensadores do movimento de negação ou da suspeita - Nietzsche, Sartre, Marx e Freud -, expressa a condição de uma obra essencialmente antitética. No prefácio do romance Serafim, por exemplo, percebemos a expressão da antítese e da negação: "O mal foi ter eu medido o meu avanço sobre o cabresto metrificado e nacionalista de duas remotas alimárias - Bilac e Coelho Neto. $\mathrm{O}$ erro ter corrido na pista inexistente" (ANDRADE, 1978, p. 131).

\footnotetext{
${ }^{2}$ Tanto Bachofen quanto Briffault foram bom combustível para alimentar a narrativa do nazismo de uma superraça, quanto o heroísmo dos soldados de Stálin (DAVIES, 2010).
} 
O trecho acima mostra o que parece uma crítica ácida à técnica e à atitude parnasiana. Ao lado de Miramar, o romance Serafim se destaca pela sátira e a pilhéria. Oswald de Andrade deixa de lado o aspecto sério que detinha o romance preso ao conservadorismo em nome de uma produção que manifestava, em ideia e em linguagem, a negação de todos os valores. Analogamente, a literatura de Oswald servia-se do estouro rabelaisiano e seu discurso "canalizava a ironia violenta, quase luta, e o seu imagismo aproveitado como arma de extraordinário ridículo." (CANDIDO, 2011a, p. 21). De modo geral, esses dois romances são a suma satírica de uma sociedade em esfacelamento.

Somando a fase da negação de Oswald de Andrade, que se confunde com a denúncia social, a sua escrita literária configura-se atravessada pelo inesperado. Neste ponto encontramos o lado mais poético do autor, a sua veia artística pulsando com mais ênfase. Nesse sentido, Candido apresenta o estilo do choque: "estilo baseado no choque (das imagens, das surpresas, das sonoridades), formando blocos curtos e às vezes simples frases que se vão justapondo de maneira descontínua, numa quebra total das sequências corridas e compactas da tradição realista". (CANDIDO, 2011b, p. 54). Tanto o estilo do choque quanto a fase de negação oswaldiana, quando trabalhadas esteticamente, abrem o espaço do literário para a penetração da história, bem como a possibilidade de um devir matriarcal.

A pesquisa histórica se utiliza de vestígios materiais que se articulam com mitos, componentes religiosos, ciência e filosofia para elaboração de um modelo capaz de desenhar os primórdios do processo civilizatório. Com esse enfoque, Gerda Lerner (1990) elaborou um esquema conceitual, a priori livre de juízos de valor, cuja questão central pretende detectar quando, como e por quais razões se produziu, historicamente, a subordinação das mulheres. A historiadora apontou como tradicionalista e androcêntrica a concepção teleológica elaborada pelo cristianismo romano que considerou a história anterior ao nascimento de Cristo como um estágio prévio da História, e a teoria darwinista, focada na pré-história, como um período de não civilidade.

A reflexão oswaldiana estaria presente dentre as explicações que apresentam a dominação masculina como fenômeno universal, natural e religioso. Uma suposta revolução acontecera conduzindo uma classe, primeiramente formada por sacerdotes, ao poder, implantando mecanismos e instituições de obediência legal e organização estatal. Fortaleceu-se, assim, uma nova organização social, a patriarcal. “... o mundo começa com uma unidade de servidão e de culto, cujo modelo é fornecido pela gente romana e por seu direito assim conceituado..." (ANDRADE, 1972, p. 89).

Estabelecendo um diálogo mais próximo entre o filósofo antropofágico e Gerda Lerner (1990), poderíamos, partindo de tais proposições, considerar que o Patriarcado não se fez repentinamente, fora desenvolvido no transcurso de quase 2500 anos, nas diversas sociedades, e não apenas no ocidente. Tomando-se 
evidências históricas, o texto filosófico se equivocaria quanto ao aparecimento das classes sociais, pois quando foi estabelecido o Patriarcado, o conceito de classe não se conceberia. Seu uso seria possível apenas a partir do advento da industrialização, desde o século XVIII.

Assim, só se pode admitir de forma aceitável a categoria do tensionamento das classes sociais num contexto exterior à sociedade industrial, no contexto da narrativa poética, a qual se desenvolve no estágio das conjecturas. Essa interpretação ganha mais força ainda quando recordamos que a Grécia, exemplificada pela República de Platão, é descrita como uma sociedade sem senhores e sem escravos.

O que seria compreendido como uma incorreção histórica é, no texto filosófico, o testemunho vivo de uma sociedade na qual o homem não dominava o homem, seu igual semelhante, “... cultura em que todos eram iguais, possuíam as coisas em comum...” (ANDRADE, 1972, p. 89).

Outro equívoco histórico residiria na afirmação de que a subordinação das mulheres coincidiria com a instituição da propriedade privada. Vestígios arqueológicos contestam a afirmação de que houve parentesco estabelecido pela consanguinidade materna, como afirmado por Oswald de Andrade. O que existiu, fora da utopia, foi o fenômeno da apropriação masculina da reprodução e sexualidade feminina “... por exemplo, na Babilônia, durante o segundo milênio a.C. os homens controlavam totalmente a sexualidade feminina...” (LERNER, 1990, p. 25).

Contudo, a garantia efetiva da paternidade da prole foi necessidade premente da burguesia para garantir a transferência da propriedade privada aos herdeiros considerados legítimos, aos de sangue, e nada mais fora mais pertinente para assegurar a fidelidade feminina, do que o mito do amor romântico. Neste sentido, a reprodução do Patriarcado (CHODOROW, 1990) funda-se na preponderância da atribuição da maternagem ao feminino.

No seio da utopia oswaldiana o pátrio poder, originariamente atribuído ao Império Romano, remonta a tempos imemoriais, o que, pela total imprecisão, poderia ser anterior à existência das sacerdotisas. A História sustenta que deusas e sacerdotisas, em sociedades do Oriente Próximo, tiveram eliminado seu poder quando já subordinadas aos homens. A união de um Deus forte com a deusa ou sacerdotisa subordinada seria anterior ao monoteísmo e à unidade de culto fornecida pelos romanos na religião e no direito. Convergem também, nesse mesmo sentido, os textos filosófico e histórico, quanto à constatação de que o Patriarcado se perpetua pela acumulação de riqueza em mãos de um grupo formado por homens. O distanciamento entre Oswald de Andrade e a historiografia repousa no fato de o primeiro não reconhecer o Patriarcado como uma realidade e uma ideologia, mas sustentar sua existência com uma argumentação imaginativa. 
Partindo dos aspectos acima considerados podemos refutar, pela ausência de evidências concretas, que tenha existido, fora do âmbito da licença poética, uma sociedade matriarcal capaz de se rivalizar com o Patriarcado. Tampouco é possível aceitar que o mundo tecnizado, proporcionador do ócio, possa restaurar em outras bases um Matriarcado que teria existido outrora, como sustenta Andrade (1972, p.129). O retorno do Matriarcado exigiria a reconstituição de uma suposta Idade do Ouro anterior ao monoteísmo, ao escravismo e à propriedade privada.

A humanidade vive, segundo o poeta que canibalizou por um instante o campo da filosofia, um segundo termo: o do homem civilizado, antítese do homem natural, que seria superado dialeticamente pela síntese - o ser humano natural tecnizado. O homem natural, ser da sociedade matriarcal oswaldiana, só existe como metáfora ou elaboração mítica capaz de demonstrar características do feminino, que não sendo naturais, mas históricas, são socialmente edificadas. Oswald de Andrade, ao historicizar o messianismo, com suas inúmeras citações de autores, revela-se de soslaio como um pensador movido por um sentimento anarco-comunista, que o conduziu à apropriação crítica de algumas teses marxengelsianas.

O retorno da devoração e do Matriarcado se reveste de simplicidade e naturalidade na imensa capacidade imaginadora do intérprete. É um exercício modernista que tentou oferecer uma solução para os impasses da sociedade patriarcal, já nos albores do século XX, mediante a “... restauração tecnizada duma cultura antropofágica” (ANDRADE, 1972, p. 129).

\section{Referências}

ANDRADE, Oswald. Novas dimensões da poesia. In: ANDRADE, Oswald. Estética e Política. São Paulo: Globo, 1992. P. 106-119.

ANDRADE, Oswald. Do Pau-brasil à antropofagia e às utopias. Rio de Janeiro: MEC/Civilização brasileira, 1972.

ANDRADE, Oswald. Manifesto Antropófago. In: ROCHA, João Cézar de Castro (Org.); RUFFINELLI, Jorge (Org.). Antropofagia hoje? Oswald de Andrade em cena. São Paulo: É realizações, 2011. P. 27-31.

ANDRADE, Mario de. O movimento modernista. In: Aspectos da literatura brasileira. São Paulo: Martins Fontes, 1975. P. 236. 
BOAVENTURA, Maria Eugenia. O salão e a selva: Uma biografia ilustrada de Oswald de Andrade. Campinas, SP: Ed. UNICAMP, 1995.

BOPP, Raul. Vida e morte da antropofagia. Rio de Janeiro: José Olympio, 2008.

BRIFFAULT, Robert, the Mothers. A study of the origins of sentiments and institutions. New York: The Macmillan Company, 1927. 3 vols.

CANDIDO, Antonio. Estouro e Libertação. In: Estouro e Libertação. 4. ed. Rio de Janeiro: Ouro sobre azul, 2011a. P. 11-27.

CANDIDO, Antonio . Digressão sentimental sobre Oswald de Andrade. In: . Vários Escritos. 5. ed. Rio de Janeiro: Ouro sobre azul, 2011b. P. 35-63.

CHODOROW, Nancy. Psicanálise da maternidade: uma crítica a Freud a partir da mulher, Rio de Janeiro: Rosa dos Tempos,199o.

DAVIES, Peter, Myth, matriarchy and modernity. Johann Jakob Bachoffen in german culture. 186o - 1945. Berlin and New York: De Gruyter, 2010.

HELENA, Lucia. Uma literatura antropofágica. 2. ed. Fortaleza: Ed. UFC, 1983.

LERNER, Gerda. La creación del patriarcado. Barcelona: Crítica, 1990.

NODARI, Alexandre. A única lei do mundo. In: ROCHA, João Cézar de Castro. Antropofagia hoje? Oswald de Andrade em cena. São Paulo: É realizações, 2011. P. $455-483$.

ROCHA, João Cézar de Castro. Uma teoria da exportação? Ou: "Antropofagia como Visão de Mundo". In: ROCHA, João Cézar de Castro. Antropofagia hoje? Oswald de Andrade em cena. São Paulo: É realizações, 2011. P. 647-668.

STERZI, Eduardo. Diante da Lei - da gramática - da história (Oswald de Andrade, poeta das exceções). Luso-Brazilian Review, New York, December 1, 2018 vol. 55 no. 2 115-130. Acesso em 20/03/2019. Disponível http://lbr.uwpress.org/content/55/2/115.full.pdf+html

*Docente do PPG Mestrado e Doutorado em Desenvolvimento Local da UCDB Universidade Católica Dom Bosco e Docente do Curso de Ciência Política no Curso de Direito da UCDB.

** Doutor em psicologia (PUC Campinas, 2004), Pós-doutorado em Estudos Culturais (USP-EACH, 2017) e Docente do Programa de Pós-Graduação em Desenvolvimento Local da Universidade Católica Dom Bosco.

${ }^{* * *}$ Doutor em Estudos Literários pela Universidade Federal de Mato Grosso do Sul (UFMS), campus Três Lagoas e Professor do curso de Letras da Universidade Estadual de Mato Grosso do Sul (UEMS). 